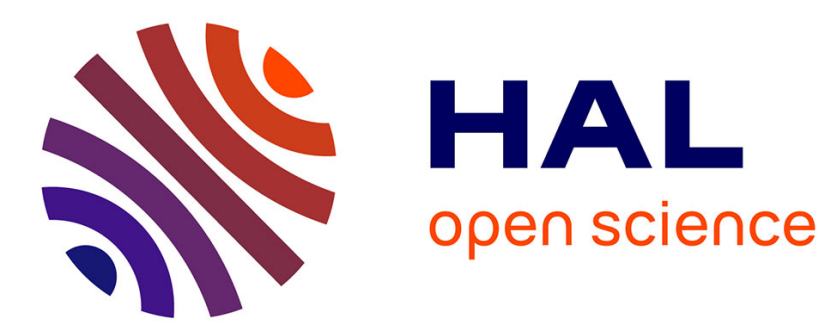

\title{
Industrial rearing of edible insects could be a major source of new biological invasions
}

\author{
Alok Bang, Franck Courchamp
}

\section{To cite this version:}

Alok Bang, Franck Courchamp. Industrial rearing of edible insects could be a major source of new biological invasions. Ecology Letters, 2020, 10.1111/ele.13646 . hal-03043276

\section{HAL Id: hal-03043276 \\ https://hal.science/hal-03043276}

Submitted on 15 Dec 2020

HAL is a multi-disciplinary open access archive for the deposit and dissemination of scientific research documents, whether they are published or not. The documents may come from teaching and research institutions in France or abroad, or from public or private research centers.
L'archive ouverte pluridisciplinaire HAL, est destinée au dépôt et à la diffusion de documents scientifiques de niveau recherche, publiés ou non, émanant des établissements d'enseignement et de recherche français ou étrangers, des laboratoires publics ou privés. 
Industrial rearing of edible insects could be a major source of new biological invasions

$3 \quad$ Alok Bang $^{\mathrm{a}, 1}$, Franck Courchamp ${ }^{\mathrm{b}}$

4

$5{ }^{\mathrm{a}}$ Department of Biological Sciences, Indian Institute of Science Education and Research,

6 Pune, 411008, India

7 bUniversité Paris-Saclay, CNRS, AgroParisTech, Ecologie Systématique Evolution, 91405,

8 Orsay, France

9

10 Running head: The downside of entomophagy

11

12 Word count: 2553 (2084 words excluding references)

13

14 Author contributions: F.C. conceived the idea; A.B. wrote the first draft of the manuscript;

15 F.C. edited it; A.B. and F.C. reviewed the manuscript for final edits.

16

17 The authors declare no competing interest.

18

$19{ }^{1}$ To whom correspondence should be addressed.

20 Current Address: A. Bang, Department of Biological Sciences, Indian Institute of Science

21 Education and Research (IISER), Pune, 411008, India. Email: alok.bang@iiserpune.ac.in. 
23 Our food habits have contributed significantly to changes in the environment. Global change

is in part fueled by excess consumption of meat, primarily of beef, which participates in deforestation (through pastures mostly in South America) and in climate change through methane emissions by livestock and massive water and food intake per kilogram of meat production (1). How ecologically sustainable is the chain of food production to food consumption is a critical socio-ecological enquiry. Entomophagy_dietary consumption of insects-is increasingly seen as a solution, as it lowers many of the global change-related consequences of the current meat-based diet of an increasing part of the human population (2). As a result, entomophagy is a rapidly emerging alternative in the global food industry for human, pet and cattle food. We contend here that since it follows the same route of industrialization and intensification than vertebrate-based traditional food production, it may add to another component of global change: biological invasions.

Currently, over two billion people in 130 countries belonging to over 3000 ethnic groups consume 1000-2200 insect species directly as a part of their traditional diets $(3,4)$. The historical negative bias towards insect consumption is now diminishing in Europe and European-driven populations, mostly due to the perceived nutritional, ecological, ethical and economic benefits (2). Insects offer several advantages over traditional non-vegetarian diet in terms of higher protein-to fat ratios, less demand during development on water and other resources, lower carbon footprint, higher conversion efficiency values, low capital investment, three-dimensional rearing possibilities, lower generation time, higher fecundity, higher resilience to diseases, and finally, a novelty in food preparations (2, 3). These positive implications of an insect-based diet have contributed to the establishment of an industry with an overall global market estimate of USD 400 million and is projected to rise to USD 700 million-1.2 billion by 2024, with major market share increases in Europe and North America $(5,6)$. 


\section{Possible Negative Implications of Industrial Insect Farming}

Insects are known to be successful invaders worldwide in most ecosystems, causing ecological and economic catastrophes costing at least 70 billion dollars annually (7). In addition to cause crop or forest destruction, and potential health hazards, invasive insects can cause damage to the native biodiversity by hybridization, by aiding the spread of pathogens, by way of trophic impacts such as predation and parasitism, and/or by competition for resources (8). Historical accumulation curves of the introduction of non-native species to newer areas of habitats, which is correlated with human-mediated species dispersal, have not yet reached saturation (9). The collapse of the thermal barrier, which historically prevented ectothermic species such as insects from invading colder habitats, has resulted in range expansions of many insect species (10) and will open new regions for invasions to many species that are escaping from industrial insect farms. All these factors highlight the importance of studying the biology and ecology of insects concerned by such mass-rearing, improving biosecurity frameworks and quarantine facilities as well as establishing adequate strategic plans, legislation, policies and budgets to contain post-border release of these potentially invasive species.

\section{Resilient Species, Tougher Eradication}

Out of the 2200 species of edible insects reported in the traditional diet around the world (4), several are currently reared industrially at a mass production level (Fig. 1) (2), and numerous other species could be expected to follow given the growth rate of the entomophagy industry. What makes the species chosen for entomophagy exceptionally dangerous is that the traits that make them appropriate for mass rearing are the very traits that could also make them successful and problematic invasive species: high fecundity, generalist feeding and nesting 
habits, resilience to climate changes and fluctuations, low resource requirements, and high disease resistance $(2,11)$.

This concern is not unfounded as it is reminiscent of many such past activities where movements of species for several commerce-driven activities has resulted in a deliberate or accidental release of non-native species, as seen in pet trade, ornamental trade, biological pest control programmes, medicinal use, species for laboratory scientific experiments and educational exhibits, fur industry, silk production, and pollination (12). There are recorded instances of exotic species imported as a food source turning into invasive species, as seen in the case of the giant African snail (Achatina fulica) (13). Other flagship examples of commerce-and industry-driven invasions include the introduction of the American mink (Neovison vison) to Europe for fur farming where the released individuals or the escapees became invasive (14). Already, several of the mass-reared insect species have become cosmopolitan in distribution and are treated as serious pests and invasive species (Fig. 1) (15). More species, or new varieties or strains of the former, could join them as the market expands.

\section{Potential areas of invasions}

While many of the existing farms and companies are located in East and Southeast Asia including China, new larger companies with considerable market share are upcoming in Europe and North America, where 15 of the top 20 companies in the edible insect market in the world are now located (16). Regardless of the region, the biosecurity on these farms is rarely of regulatory standards to prevent or respond to unintentional escapes. Given the ease of rearing insects, many of these facilities have an annual turnover of rearing millions of individuals (Fig. 2) (17). Even if a tiny percentage of these individuals manage to escape, it 
97 still contributes towards a sizable founder population, one that has been selected for being fast-growing at both the organism and population levels.

\section{Policy and Implementation Loopholes}

Most existing international policy and guiding principles related to the movement, rearing and escapes of non-native species take into account economic impacts in managed ecosystems such as agriculture, livestock and fisheries. The economic and biodiversity losses in natural ecosystems are likely higher and also difficult to quantify, and yet, they do not come under the direct purview of many of these policies.

These guiding principles are also strewn with certain ambiguities which allow movements of non-native species under technical loopholes. For example, under the invasive species guiding principles exercised in the European Union, deliberate introductions of organisms are to be prevented, but regulation over accidental introductions are not exercised. Another example is of The Convention on International Trade on Endangered Species of Flora and Fauna (CITES) which prevents the importation of invasive species, but there is no regulation on captive breeding and pet industry within whose purview the species reared for entomophagy might be reared and sold (8). In some instances, the policies of different international agencies are in direct conflict with each other, such as those of the World Trade Organization (WTO) promoting an unrestricted movement of products and those of the Convention on Biological Diversity (CBD) and CITES promoting regulation of these movements (18).

Low prioritisation by nation-states to implement international guiding policies and principles is another likely cause of biological invasions, as seen for example, of low prioritisation in European Union of article 8(h) of Convention on Biological Diversity (CBD) 
dealing with non-native species, which results in fewer resources directed to regulate movements of species (8).

While food safety-related risk assessment is increasingly exercised when for human consumption (19), regional and local invasion risk assessment and management protocols are not readily available for specific species, habitats or pathways of introduction, especially when for animal feed, even in developed countries. This often results in directives for a minimal set of notorious species which are blacklisted. A species not on the 'blacklist', only because of its unassessed nature, could still be mass-reared and accidentally released $(17,20)$. Finally, the biosecurity status of these rearing facilities is worrying. Inferior, diseased or unrequired stocks should be destroyed but are often released in the environment (17). Numerous escapees have been reported in the south- and south-east Asia (21). Even in highincome countries where the rearing facilities could be more rigorous towards containment, low awareness and commitment on the part of the stakeholders often result in illegal selling, frequent and high numbers of escapees, and absence of monitoring and early response programs increase establishment and spread (17).

\section{Avoiding New Invasions: The Way Forward}

International policies and guiding principles need to include certification, quarantine, postentry monitoring and early response programs. The development of protocols of impact riskassessment is essential because it assists in classifying species based on different risk categories, from low to high risk of invasion, as has been practised in island nations such as Australia and New Zealand (22). These island nations also have a more rigorous approach towards importing any living species, by developing a 'whitelist', wherein every non-native species is considered potentially dangerous till proved to be safe by a risk profiling. In contrast, the more widely implemented approach of a 'blacklist', wherein every species is 
acceptable for import unless specifically banned, relies on scientists needing to prove that a species is problematic, with all the associated caveats when it would go against economic pressure. Adopting a 'whitelisting' approach is more stringent and hence more effective in controlling potential invasions (20); it is also more logical as the assessment would need to be done only for species considered for the industry.

Eventually, the mass rearing facilities should be developed on the lines of pathogen housing facilities, where pathogens are broadly classified into four different biosafety levels based on their pathogenicity and potential impacts. areas of habitats, in regions which lack sufficient regulatory frameworks, and in facilities 
especially important looking at the growth prospects of this industry in the future, lack thereof we might be standing at the precipice of a new solution turned-on-its-head to become a threat to global biodiversity.

Acknowledgements

A.B. acknowledges support by the postdoctoral fellowship from Indian Institute of Science Education and Research, Pune; F.C. is supported by the Invasion Biology AXA Chair and the AlienScenario Biodiversa project. F.C. conceived the idea of this piece while at the 2018 ANDINA IV Workshop and would like to thank the organizers for their invitation to this stimulating meeting.

\section{References}

1. Westhoek H et al. (2011) The protein puzzle (The Hague: PBL Netherlands Environmental Assessment Agency).

2. van Huis A (2013) Potential of insects as food and feed in assuring food security. Annu Rev Entomol 58:563-583.

3. Ramos-Elorduy J (2009) Anthropo-entomophagy: cultures, evolution and sustainability. Entomol Res 39:271-288.

4. Jongema Y (2017) List of edible insects of the world. Wageningen Univ. Available at: https://www.wur.nl/en/Research-Results/Chair-groups/Plant-Sciences/Laboratory-ofEntomology/Edible-insects/Worldwide-species-list.htm.

5. Dunkel F V, Payne C (2016) in Insects as sustainable food ingredients: production, processing and food applications, eds Dossey AT, Morales-Ramos JA, Rojas MG 
6. Persistence Market Research (2016) Edible insects market-Global industry analysis and forecast 2016-2024.

7. Bradshaw CJA et al. (2016) Massive yet grossly underestimated global costs of invasive insects. Nat Commun:12986.

8. Hulme PE (2007) in Biodiversity under threat, eds Hester R, Harrison R, pp 56-80.

9. Seebens $\mathrm{H}$ et al. (2017) No saturation in the accumulation of alien species worldwide. Nat Commun 8:14435.

10. Bellard C et al. (2013) Will climate change promote future invasions? Glob Chang Biol 19:3740-3748.

11. Ricciardi A et al. (2017) Invasion science: a horizon scan of emerging challenges and opportunities. Trends Ecol Evol 32:464-474.

12. Kumschick S et al. (2016) Intentionally introduced terrestrial invertebrates: patterns, risks, and options for management. Biol Invasions 18:1077-1088.

13. Raut SK, Barker GM (2002) in Molluscs as crop pests, ed Barker GM (CABI Publishing), pp 55-114.

14. Bonesi L, Palazon S (2007) The American mink in Europe: status , impacts , and control. Biol Conserv 134:470-483.

212 15. Fiaboe K, Peterson A, Kairo M, Roda A (2012) Predicting the potential worldwide distribution of the red palm weevil Rhynchophorus ferrugineus (Olivier) (Coleoptera: Curculionidae) using ecological niche modeling. Florida Entomol 95:659-673. 
16. Dossey AT, Tatum JT, McGill WL in Insects as sustainable food ingredients: production, processing and food applications, eds Dossey AT, Morales-Ramos JA, Rojas MG (Academic Press), pp 113-152.

17. Weissman DB, Gray DA, Pham HT, Tijssen P (2012) Billions and billions sold: petfeeder crickets (Orthoptera: Gryllidae), commercial cricket farms, an epizootic densovirus, and government regulations make for a potential disaster. Zootaxa 3504:67-88.

18. Tømmerås BÅ et al. (2001) Globalisation and invasive alien species.

19. SLU, Swedish University of Agricultural Sciences, Department of Biomedical Sciences and Veterinary Public Health S et al. (2018) Novel foods: a risk profile for the house cricket (Acheta domesticus). EFSA J 16:e16082.

20. Simberloff D (2006) Risk assessments, blacklists, and white lists for introduced species: are predictions good enough to be useful? Agric Resour Econ Rev 35:1-10.

21. AFP (2013) One million cockroaches escape from Chinese farm. Telegr. Available at: https://www.telegraph.co.uk/news/worldnews/asia/china/10264868/One-millioncockroaches-escape-from-Chinese-farm.html [Accessed December 12, 2019].

22. Hulme PE et al. (2018) Integrating invasive species policies across ornamental horticulture supply chains to prevent plant invasions. J Appl Ecol 55:92-98. 


\section{Figure Legends}

236 Fig. 1. Some of the most popularly consumed and industrially reared insect species, their 237 recipes and the damage they are already reported to cause. (A-C) palm weevil

238 (Rhynchophorus ferrugineus), raw larvae or their soup, and, their infestation causing 239 mortality of the palms; (D-F) litter beetle (Alphitobius diaperinus), burger made from its

240 larvae, and its infestation of poultry houses; (G-I) desert locust (Schistocerca gregaria), 241 locust taco, and the locust swarms causing substantial crop damages and thereby impacting 242 food security. Image courtesy of Wikimedia Commons and Food and Agriculture 243 Organization (FAO).

245 Fig. 2. Insect rearing facilities. (A, B) Small rearing centres, and, (C, D) large industrial 246 rearing facilities. Despite the differences in sophistication in rearing techniques, both types 247 of rearing facilities lack tight biosecurity measures. Image courtesy of Food and Agriculture 248 Organization (FAO). 
Figures

$250 \quad$ Fig. 1.

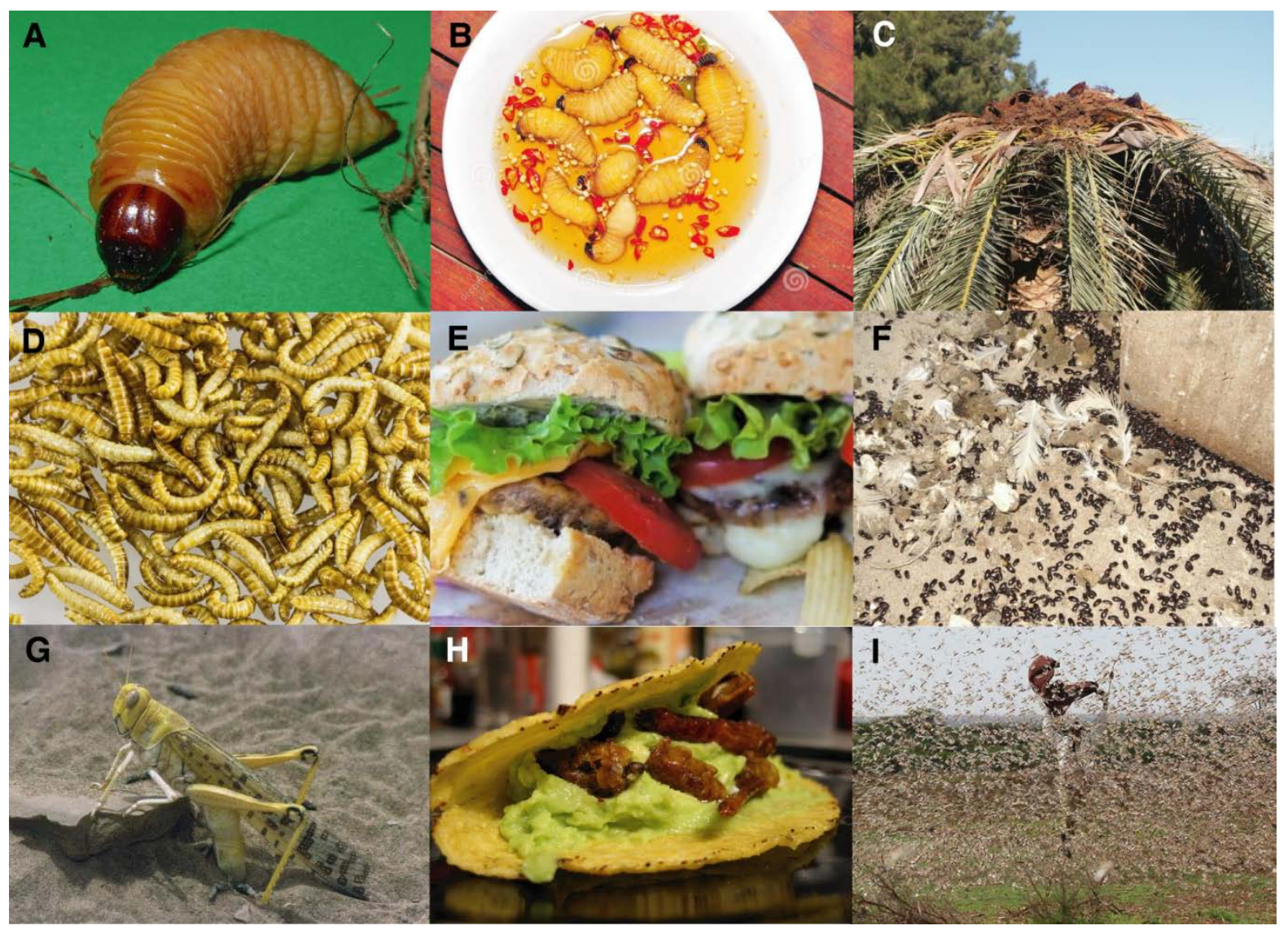

252 
$253 \quad$ Fig. 2.

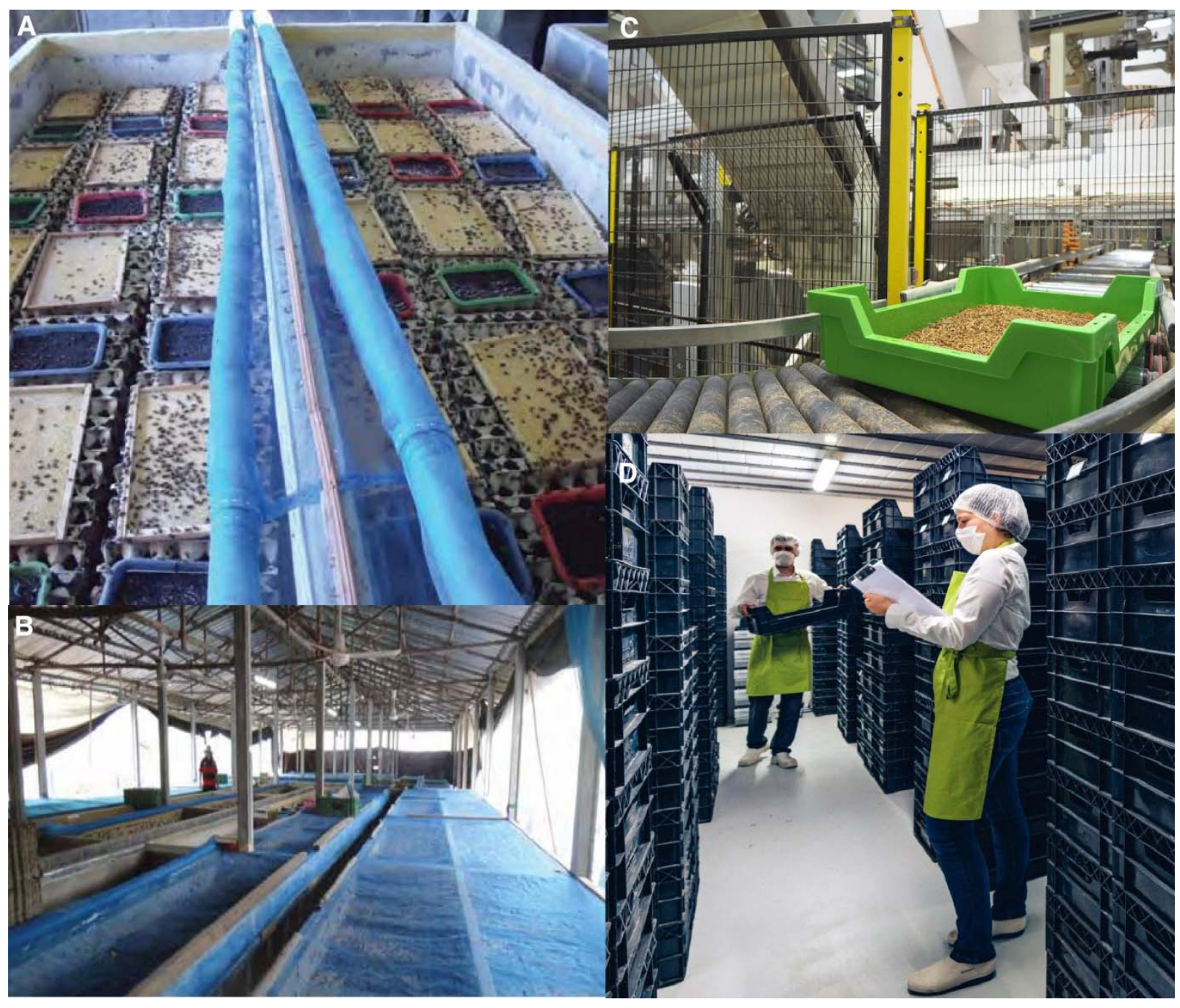

